\title{
GENTRIFICACIÓN Y TURISTIFICACIÓN: ORIGEN COMÚN, EFECTOS DIFERENTES
}

\author{
ADRIÁN HERNÁNDEZ CORDERO \\ adn212@gmail.com \\ Universidad Autónoma Metropolitana, Iztapalapa
}

En el texto se presenta el debate entre gentrificación y turistificación. Ambos fenómenos comparten un origen común, pero tienen implicaciones diferentes en la ciudad. La aproximación metodológica consiste en una revisión bibliográfica; primero se reflexiona sobre la reconfiguración de las ciudades y posteriormente se discute sobre los conceptos de gentrificación y turistificación. Enseguida, se realiza un ejercicio comparativo entre ambas. Finalmente, se discute cómo los fenómenos abordados producen el desplazamiento de habitantes, aunque se diferencian en que la gentrificación implica la llegada de residentes de mayores ingresos, mientras que la turistificación se caracteriza por el arribo de población flotante.

Palabras clave: turismo, ciudades, desplazamiento, residentes, consumo.

\section{GENTRIFICATION AND TOURISTIFICATION: COMMON ORIGIN, DIFFERENT EFFECTS}

The debate between gentrification and touristification is discussed. Both share a common origin but have different implications in the city. The methodology consists of a bibliographic review; first, we reflect on the transformation of cities. Subsequently, the concept of gentrification and touristification is discussed. Then, a comparative exercise between the two is carried out. Finally, it is discussed how the phenomena addressed produce the displacement of inhabitants, although they differ in that gentrification implies the arrival of higher-income residents, while touristification is characterized by the arrival of a floating population.

Keywords: tourism, cities, displacement, residents, consumption. 


\section{Introducción}

as ciudades viven un proceso de reorganización territorial, económica y social, derivado de la irrupción del neoliberalismo en los años 70 del siglo pasado. Al respecto, Smith (2015) argumenta que la globalización impulsó la configuración de un nuevo urbanismo, lo cual implicó una mayor influencia de factores endógenos sobre la producción y reproducción urbana. Paralelamente, las ciudades han ido adquiriendo mayor peso en el tablero mundial por las actividades que aglutinan, así como por la cantidad de población con la que cuentan, ya que actualmente un mayor número habita en zonas urbanas.

Han ocurrido cambios en las grandes metrópolis que las han llevado a priorizar el sector servicios, a partir de los intereses del capital financiero transnacional. Igualmente, ha sido importante la confección de políticas urbanas impulsadas por organismos supranacionales y su posterior circulación en el globo (Smith, 2015). En este contexto, se han redescubierto espacios tales como los centros históricos que durante la segunda mitad del siglo pasado comenzaron a vivir fenómenos de desinversión y pauperización.

En su momento Porter (1995) indicó que en las ciudades anglosajonas los Distritos Centrarles de Negocios (CBD) debían ser rescatados por las ventajas competitivas (localización e infraestructura) que representaban para las metrópolis, en el marco de una amplia competencia internacional para buscar la atracción de inversionistas; mientras que en ciudades europeas y latinoamericanas en algunos casos se reforzaron, en otros se impulsaron políticas de patrimonialización con la finalidad de insertar un producto turístico en el circuito de la economía global, al respecto son ilustrativas las investigaciones de Delgadillo (2009) sobre la Ciudad de México.

Las acciones mencionadas implicaron cambios en las ciudades, sobre todo en zonas como los centros históricos y barrios longevos en los cuales se ha llevado a cabo una profunda transformación con efectos como la gentrificación y la turistificación. Ambos fenómenos se encuentran en el centro del debate de los estudios urbanos, por lo que gran cantidad de tinta ha corrido para discutirlos, sobre todo en los países anglosajones y en el Estado español para el caso del ámbito castellanoparlante. Una buena muestra de ello es la complicación de Milano y Mansilla (2018) así como Delgadillo et al. (2015). 


\section{Gentrificación}

En los últimos años el concepto de gentrificación ha sido el protagonista de uno de los debates más candentes en los estudios urbanos, ya sea por ser un anglicismo, por retomar una palabra de un contexto anglosajón para estudiar contextos diferentes, o bien por reciclar viejas cuestiones como la marginación en un vocablo distinto.

Dichos aspectos por ahora se encuentran fuera del foco de este texto, pero más allá de los argumentos apasionados es una realidad que el intercambio de ideas ha servido, desde la perspectiva de Slater (2011), para evidenciar las injusticias y desigualdades sociales originadas por las políticas de suelo urbano que imperan en el marco del urbanismo neoliberal. Asimismo, la discusión ha sido útil para analizar la revitalización de las áreas centrales de las ciudades, una tendencia que se ha manifestado en diversas urbes del planeta y en la que convergen actores a escalas local y global.

La voz gentrificación tiene más de cinco décadas de existencia, fue acuñada desde la sociología para estudiar los procesos de transformación social mediante los cuales sectores de clase media comenzaron a interesarse, adquirir viviendas y mudarse a barrios obreros en Londres (Smith, 1996; Slater, 2011). La llegada de los nuevos pobladores trajo consigo la salida de los habitantes antiguos de menores ingresos, situación que transfiguró la fisonomía de los sectores urbanos en cuestión. Entonces, la gentrificación puede entenderse como un fenómeno de cambio demográfico que se construye de manera dialéctica y que tiene profundas repercusiones espaciales. Según Casgrain y Janochska (2013) la gentrificación ocurre cuando se cumplen las siguientes características:

1) La inversión financiera se aplica en un sector de la ciudad para buscar revalorizarlo, que suele contar con el respaldo empresarial y con políticas urbanas hechas a medida por los poderes públicos.

2) La llegada de personas de clase media, con ingresos superiores a los antiguos habitantes, con un alto capital cultural y, por ende, patrones de consumo diferenciados y diferenciadores con el resto de la población.

3) La mutación de la estructura comercial como resultado de los nuevos patrones de consumo de los recién llegados, modificando la configuración paisajística del barrio y que tiende a presentar símbolos reconocidos por los colectivos cosmopolitas. 
4) El desplazamiento directo de los antiguos vecinos, así como el incremento de los mecanismos de presión (aumentos del costo de la vida y la violencia inmobiliaria) para completar la transformación del barrio en cuestión.

No está de más decir que debido al auge de la gentrificación cada vez más se han incorporado temáticas como su relación con la gastronomía, la preferencia sexual e incluso se han estudiado manifestaciones como la denominada gentrificación de nueva construcción que se interesa por la verticalización en solares, o bien la edificación en antiguas zonas industriales en la periferia. Sin duda cuestiones interesantes, pero que merecen ser discutidas en otro momento.

\section{Turistificación}

La década de los 90 del siglo pasado tuvo vertiginosos cambios, uno de ellos fue el incremento de los flujos de desplazamiento internacionales con motivos de ocio. El turismo que hasta hace no mucho tiempo tuvo tintes elitistas se fue democratizando, gracias a la reducción de los costos de los pasajes de avión, así como a la conclusión de las restricciones de movilidad que impuso el mundo bipolar. En este contexto, diversos sitios del planeta se fueron transformando debido al incremento de la actividad turística a la cual apostaban los gobiernos nacionales y supranacionales, como vía de crecimiento económico.

Cañada y Murray (2019) señalan que los sectores académicos en mayor medida, más que analizar los impactos del turismo prácticamente fueron voceros de las políticas gubernamentales, al igual que de los grupos empresariales para promover su aceptación social, evitando la difusión de cualquier enfoque crítico. En este sentido, se comenzó a reflexionar sobre la manera en que la actividad turística repercutió en diferentes ámbitos de los espacios receptores, así empezó a cuestionarse la denominada capacidad de carga turística; es decir, la cantidad máxima de turistas que puede recibir un sitio sin generar grandes impactos medioambientales y sociales.

En este marco, desde la geografía francófona se acuñó el término turistificación, el cual puede entenderse según Knafou $(1992 ; 1999)$ como el proceso mediante el cual un sitio se convierte en un enclave turístico. Dicha mutación incluye la dimensión física (construcción de infraestructura y equipamiento) e imaginaria (generación de imágenes y representaciones). De acuerdo con De la Calle (2019) puede hablarse de turistificación cuando se cumplen las siguientes condiciones: 
1) Mayor presencia en el espacio e infraestructura pública de visitantes (pernoctantes y excursionistas) y sus actividades vinculadas con el ocio en ciertas zonas de la ciudad, que aglutina los elementos con valor patrimonial o de interés turístico.

2) La actividad turística genera una demanda de servicios que debe ser cubierta. Progresivamente se crean establecimientos que satisfacen las necesidades (hospedaje, alimentación, servicios, etcétera) de la población foránea.

3) La adaptación de la oferta comercial; es decir, los establecimientos que atendían a la población local cambian y adaptan su giro comercial para atraer a los turistas, a quienes se considera como potenciales clientes, por lo que los negocios experimentan cambios en sus precios, horarios, acceso a internet e incluso idiomas de atención.

4) Una mayor presencia de turistas en combinación con el surgimiento de plataformas que ofrecen alojamiento generan una adaptación de la vivienda al sector turístico. Se produce el desplazamiento de población y vaciamiento de barrios debido a lo redituable que resulta insertar las moradas en el mercado de población flotante.

La apuesta al turismo de un espacio tiene profundas y veloces mutaciones que en ocasiones, según el caso, pueden generar tensiones y conflictos entre los residentes y la industria turística. Esta situación ha generado que el término se asocie con un enfoque negativo respecto al turismo y haya sido adoptado por académicos críticos y movimientos sociales, postura que rivaliza evidentemente con los promotores, privados y públicos, del turismo (Calle, 2019; Díaz y Sequera, 2021).

\section{Gentrificación versus turistificación}

Puestas las cartas sobre la mesa, parece claro que gentrificación y turistificación son expresiones urbanas diferenciadas. Arias (2018) sostiene que los trabajos sobre el primer término pensaban al turismo como una secuela de la transformación de los centros urbanos, mientras que los partidarios del segundo bloque habían prestado poca atención a los efectos del turismo como elementos gentrificadores.

Sin embargo, recientemente ha surgido un debate dinamizado por investigadores urbanos, primero en el ámbito anglosajón y posteriormente en el Estado español. Esta situación no es casual, ya que el país ibérico es uno de los principales receptores 
turísticos del mundo, trayendo consigo múltiples implicaciones que han puesto bajo la lupa los efectos del turismo, sobre todo en el espacio urbano; como evidencia está la publicación del monográfico coordinado por Díaz y Sequera (2021). Así, quienes comenzaron a interesarse por la gentrificación ampliaron sus intereses y analizaron los efectos del turismo en las grandes ciudades como Barcelona, Madrid, Sevilla, así como en urbes medias, tal es el caso de Granada o Santiago de Compostela.

En este contexto, De la Calle (2019) indica que desde los estudios urbanos se considera al turismo como un vector de transformación urbana. Al respecto, comenzaron a plantearse entrecruzamientos entre gentrificación y turisitificación, a tal grado que Gotham (2005) acuñó el término provocador de "gentrificación turística", que se entiende como la transformación de un sector de la ciudad a partir de la proliferación de establecimientos y actividades turísticas, generando un proceso de desplazamiento de los residentes. Debido al cambio demográfico que implica la sustitución de vecinos es que dicho autor considera que el fenómeno analizado puede explicarse a partir de la gentrificación.

Al respecto hay diferentes posturas: desde una acera se encuentran quienes dan por bueno el concepto, como Cocola-Gant (2018) quien considera que el turismo es un generador de la gentrificación, aunque resalta las diferencias entre países ricos y pobres; en los primeros los límites son porosos entre gentrificación y turismo, ya que los sujetos gentrificadores son atraídos por los paisajes sanitizados de las zonas centrales, mientras que en los segundos se hace más evidente el fenómeno de la gentrificación turística, debido a que la ausencia de clases medias genera que sean los viajeros (jóvenes, cosmopolitas y con patrones de consumo global) quienes asuman el papel de impulsores del proceso de mutación.

Desde el ámbito latinoamericano, Hiernaux-Nicolas y González (2014) coinciden en que no son las clases medias quienes producen la gentrificación de los centros históricos, sino que la gentrificación turística es el resultado de la implementación de políticas públicas. Estas tienen como finalidad llevar a cabo procesos de renovación urbana que implican el desplazamiento de prácticas populares. Igualmente, más que atraer habitantes se enfocan en ser sugestivas para los turistas. Los autores consideran que los viajeros, a pesar de su presencia efímera, deben considerarse como los nuevos habitantes de los barrios centrales que dotan de significados a estos espacios a través de sus prácticas, las cuales resulta cada vez más complicado diferenciar de las de los residentes, sobre todo aquellos bohemios. 
La gentrificación turística tiene además efectos en el mercado inmobiliario, al respecto Hiernaux-Nicolas (2018) menciona cómo desde el comienzo del fenómeno se pueden identificar cambios como el incremento del precio de alquiler, la venta de inmuebles para dedicarlos a las actividades turísticas y, por lo tanto, la modificación de usos de suelo. Mansilla (2019) señala asimismo que la gentrificación turística se diferencia de la convencional debido a que el rent gap (comprar barato para vender caro) no se establece a partir del bajo valor del suelo por su abandono, sino que funciona a través de las altas expectativas de inversionistas por obtener dividendos. Existe constancia de que el valor del suelo de un sector de la ciudad dedicado a la actividad turística ofrece mejores rendimientos que el de un barrio residencial, debido a la cantidad de personas que visitan y consumen en las áreas de turismo.

Desde otro ángulo de visión, existen autores que consideran endeble el término gentrificación turística. Sequera (2020) sostiene que el propio término proviene del abuso de la palabra gentrificación, la cual se ha utilizado para nombrar múltiples fenómenos que implican la elitización. Asimismo, considera que a pesar de que ciertos barrios de ciudades del sur de Europa se están transformando en sitios de consumo y servicios turísticos, no necesariamente se producen procesos de gentrificación. El concepto de gentrificación turística, de indudable éxito en cuestiones de marketing mediático y académico, puede acabar convirtiéndose en un lastre que limite las posibilidades de aproximación al estudio del turismo y sus efectos en la ciudad.

El principal argumento que sostienen los partidarios de la gentrificación turística es que se genera desplazamiento de población pobre; no obstante, De la Calle (2019) piensa que este argumento es endeble, ya que tanto la expulsión ocasionada por la aparición de establecimientos turísticos como por las actividades de los visitantes afectan al conjunto de los moradores. El incremento del valor del suelo a la par del costo de los servicios y productos básicos resulta tan alto que termina afectando y expulsando al conjunto de las clases sociales. De igual manera, hay que añadir las particularidades de vivir en un enclave turístico que representan la dificultad para abastecerse de productos cotidianos por la desaparición de tiendas y colmados ${ }^{1}$, así como por la presencia masiva de turistas y en algunas ocasiones por sus conductas incívicas.

Jover y Díaz (2019) argumentan que la gentrificación y la turistificación son fenómenos distintos en su esencia. El primero consiste en el reemplazo de pobladores de origen obrero por otros de mayor estatus, mientras que la turistificación se define por el incremento de la actividad turística pudiendo ocasionar la pérdida de

1 En España, establecimiento donde se venden comestibles y otros productos. 
residentes, aunque no implica el reemplazo a largo plazo. Por lo tanto, los autores sugieren pensar que la turistificación ocasiona el desplazamiento de población, así como de elementos físicos y simbólicos, de tal manera que se afecta la habitabilidad de los barrios turísticos, generando que los usos residenciales suelan ser incompatibles con las actividades del turismo de masas.

\section{Apuntes finales: un origen común, efectos distintos}

A lo largo de la nota crítica se sostuvo que la gentrificación y la turistificación son cuestiones diferentes. Ambas manifestaciones responden a un proceso común caracterizado por la reconfiguración económica, política y territorial de las ciudades, a partir de la implementación del urbanismo neoliberal, el cual (re)incorporó espacios como los centros históricos o frentes marítimos a los circuitos económicos del capital, debido a su potencial estratégico y económico en una época marcada por la competencia global, que genera que las metrópolis busquen la atracción de capital financiero y humano. De la Calle (2019) muestra cómo la gentrificación y la turistificación están relacionadas en su origen, pero no en sus efectos. Al hilo de este argumento se construye la tabla 1, la cual intenta mostrar las principales diferencias entre los conceptos que se han discutido.

Tabla 1. Diferencias entre gentrificación y turistificación

\begin{tabular}{c|c|c} 
& Gentrificación & Turistificación \\
\hline Población & Desplazamiento y sustitución & Flotante y posible desplazamiento \\
\hline Usos del suelo & Residencial e infraestructura cultural & Turísticos y patrimonial \\
\hline Comercio & Gastronomía, galerías y ocio & Hoteles, gastronomía y souvenirs \\
\hline Vivienda & Residencial (larga estancia) & Vacacional (corta estancia) \\
\hline & Fuente: Elaboración propia. & \\
\hline
\end{tabular}

La tabla 1 resume los principales argumentos esgrimidos en estas líneas. Manifiesta que existen diferencias entre la gentrificación y la turistificación: la primera atrae habitantes y aunque no pocos académicos están de acuerdo con sus pautas de consumo y sus estilos de vida, estos generan, como diría Mansilla (2019), un tejido social estable. Ejemplo de ello es el caso del barrio Madrileño de Lavapiés, en el que se han generado alianzas entre los habitantes nuevos y antiguos para confrontar los efectos de la gentrificación. Mientras que la segunda no produce relaciones sociales intensas por su carácter efímero e incluso contribuye con el rompimiento de los lazos comuni- 
tarios. En este contexto, los vecinos se han vuelto una especie en peligro de extinción, como han sostenido los pocos moradores del Barrio Gótico de Barcelona, el cual ha sido asaltado por los efectos del turismo, principalmente por los fondos de inversión que actúan a través de las plataformas digitales de alquiler de corta duración.

En fin, sirvan estas notas para cuestionar cómo se viven estos procesos en las realidades latinoamericanas y abrir un debate en los estudios turísticos mexicanos. Los destinos turísticos nacionales no están exentos del conflicto urbano, al contrario, en su construcción se han generado importantes tensiones en las que chocan diversas miradas sobre el territorio y el turismo, como lo demostraron Hernández y Fenner (2018) para el caso de San Cristóbal de las Casas. Las disputas también se comienzan a hacer evidentes en zonas de urbes como Oaxaca, Mérida, Mazatlán o San Miguel de Allende, en las que parecen existir indicios de una masificación de visitantes.

Poner el foco en fenómenos como la gentrificación y la turistificación inaugura vetas de investigación que contribuyen a desentrañar la complejidad de las dinámicas de transformación social y entender la manera en que se "rearticulan" las ciudades y sus actores en la etapa neoliberal.

\section{Referencias}

Arias, A. (2018). Turismo y gentrificación. Apuntes desde Barcelona. Papers, 60, $130-$ 139. https://bit.ly/3hS50WX

De la Calle, M. (2019). Turistificación de centros urbanos: clarificando el debate. Boletín de la Asociación Española de Geografía, 83(2829), 1-40. https://doi. org/10.21138/bage.2829

Cañada, E. y Murray, I. (2019). Introducción. En E. Cañada e I. Murray (Eds.), Turistificación global (pp. 7-25), Icaria. https://bit.ly/3bUcgOv

Casgrain, A. y Janoschka, M. (2013). Gentrificación y resistencia en las ciudades latinoamericanas. El ejemplo de Santiago de Chile. Andamios, 10(22), 19-44. http://dx.doi.org/10.29092/uacm.v10i22.265

Cocola-Gant, A. (2018). Tourism gentrification. En L. Lees y M. Phillips (Eds.), Handbook of gentrification studies (pp. 281-293). Edward Elgar Publishing. https:// bit.ly/3fGMVIE

Delgadillo, V. (2009). Patrimonio urbano y turismo cultural en la Ciudad de México: las chinampas de Xochimilco y el centro histórico. Andamios, 6(12), 69-94. http://dx.doi.org/10.29092/uacm.v6i12.135 
Delgadillo, V., Díaz, I. y Salinas, L. (2015). Perspectivas de la gentrificación en México y América Latina. Universidad Nacional Autónoma de México.

Díaz, I. y Sequera, J. (2021). Introducción al número especial Turistificación y transformación urbana. Cuadernos Geográficos, 60(1), 6-12. https://doi.org/ 10.30827/cuadgeo.v60i1.14067

Gotham, K. F. (2005). Tourism gentrification: the case of New Orleans Vieux Carre (french quarter). Urban Studies, 42(7), 1099-1121. http://dx.doi.org/ 10.1080/00420980500120881

Jover, J. y Díaz, I. (2019). Gentrification, transnational gentrification and touristification in Seville, Spain. Urban Studies, 57(15), 3044-3059. https://doi. org/10.1177/0042098019857585

Hiernaux-Nicolas, D. (2018). Presentación. Turismo y centros históricos: un dossier decadente. Estudios críticos del desarrollo, 8(14), 7-21. https://doi.org/10.35533/ ecd.0814.dhn

Hiernaux-Nicolas, D. y González, I. (2014). Turismo y gentrificación: pistas teóricas sobre una articulación. Revista de Geografía Norte Grande, 58, 55-70. https:// bit.ly/3fQk6JU

Knafou, R. (1992). L'invention du tourisme. En A. Bailly, R. Ferras y D. Pumain (Coords.), Encyclopédie de Géographie (pp. 827-844). Económica.

Knafou, R. (1999). Turismo e território. Por uma abordagem científica do turismo. En A. Rodrigues (Org.), Turismo e geografia: reflexões teóricas e enfoques regionais (pp. 62-74), Hucitec.

Mansilla, J. (2019). Turismo y gentrificación. La reestructuración social, económica y espacial de tres ciudades de Europa y América Latina. Tendencias Sociales, Revista de Sociología, 4, 5-25. http://dx.doi.org/10.5944/ts.4.2019.25254

Porter, M. (1995). The competitive advantage of inner cities. Harvard Business Review, 55-71. https://bit.ly/3yHLH8M

Slater, T. (2011). Gentrification of the city. En G. Bridge y S. Watson (Eds.), The New Blackwell companion to the city (pp. 571-585). Wiley-Blackwell. https://bit.ly/ 3vyT3JJ

Smith, N. (2015). Nuevo globalismo y nuevo urbanismo. La gentrificación como estrategia urbana global. En Observatorio Metropolitano de Madrid (Ed.), El mercado contra la ciudad (pp. 245-270). Traficantes de sueños. https://bit. ly/3ujl7hS 